\title{
Hyperactivation of Ha-ras oncogene, but not Ink4a/Arf deficiency, triggers bladder tumorigenesis
}

\author{
Lan Mo, ${ }^{1}$ Xiaoyong Zheng, ${ }^{1}$ Hong-Ying Huang, ${ }^{1}$ Ellen Shapiro, ${ }^{1}$ Herbert Lepor, ${ }^{1,2}$ \\ Carlos Cordon-Cardo, ${ }^{3}$ Tung-Tien Sun, ${ }^{1,2,4,5}$ and Xue-Ru Wu $\mathbf{~}^{1,6}$
}

\begin{abstract}
${ }^{1}$ Department of Urology and 2Department of Pharmacology, New York University Cancer Institute, New York University School of Medicine, New York, New York, USA. ${ }^{3}$ Division of Molecular Pathology, Memorial Sloan-Kettering Cancer Center, New York, New York, USA. ${ }^{4}$ Department of Cell Biology and ${ }^{5}$ Department of Dermatology, New York University Cancer Institute, New York University School of Medicine, New York, New York, USA. ${ }^{6}$ Manhattan Veterans Affairs Medical Center, New York, New York, USA.
\end{abstract}

\begin{abstract}
Although ras is a potent mitogenic oncogene, its tumorigenicity depends on cellular context and cooperative events. Here we show that low-level expression of a constitutively active Ha-ras in mouse urothelium induces simple urothelial hyperplasia that is resistant to progression to full-fledged bladder tumors even in the absence of Ink4a/Arf. In stark contrast, doubling of the gene dosage of the activated Ha-ras triggered earlyonset, rapidly growing, and $100 \%$ penetrant tumors throughout the urinary tract. Tumor initiation required superseding a rate-limiting step between simple and nodular hyperplasia, the latter of which is marked by the emergence of mesenchymal components and the coactivation of AKT and STAT pathways as well as PTEN inactivation. These results indicate that overactivation of $\mathrm{Ha}$-ras is both necessary and sufficient to induce bladder tumors along a low-grade, noninvasive papillary pathway, and they shed light on the recent findings that ras activation, via point mutation, overexpression, or intensified signaling from FGF receptor 3, occurs in $70 \%-90 \%$ of these tumors in humans. Our results highlight the critical importance of the dosage/strength of Ha-ras activation in dictating its tumorigenicity - a mechanism of oncogene activation not fully appreciated to date. Finally, our results have clinical implications, as inhibiting ras and/or its downstream effectors, such as AKT and STAT3/5, could provide alternative means to treat low-grade, superficial papillary bladder tumors, the most common tumor in the urinary system.
\end{abstract}

\section{Introduction}

Cell growth is normally under the tight control of positive regulators (protooncogenes and growth factors) and negative regulators (senescence- and apoptosis-inducing molecules and tumor suppressors) of cell-cycle progression. It is the intricate balance between these 2 opposing forces that ensures the necessary tissue renewal while maintaining homeostasis (1). Such a balance is not static, but rather is quite dynamic, particularly when cells are called upon to respond to various pathogenic insults. For instance, when an oncogene is mutationally activated, affected cells can turn up senescence and tumor suppressor genes to counter the oncogenic effects, thereby regaining cell-cycle control and putting a brake on cell proliferation (2). Failure to do so could lead to uncontrolled proliferation and tumorigenesis. Hence, it is not surprising that oncogene activation is frequently found to be cooperative with tumor suppressor inactivation in inducing tumors in humans and animal models. However, exactly what type(s) of collaborative partners are involved and how they interact with one another to trigger tumors in a specific tissue may depend on the cellular context (3). Moreover, evidence remains scant as to whether the strength of oncogene activation per se can tip the balance between pro- and antiproliferative forces, thus altering the course of tumor development. Historically, far more attention has been paid to qualita-

Nonstandard abbreviations used: PTEN, phosphatase and tensin homolog; RTK, receptor tyrosine kinase; UPII, uroplakin II.

Conflict of interest: The authors have declared that no conflict of interest exists. Citation for this article: J. Clin. Invest. 117:314-325 (2007). doi:10.1172/JCI30062. tive alterations (i.e., mutations and deletions) of genes involved in tumorigenesis than to quantitative ones (i.e., overexpression and amplification), even though the latter are equally prevalent in a variety of human tumors $(4,5)$.

Ras, discovered in 2 urothelial cancer cell lines, was the first named human oncogene (T24 and EJ) in the early 1980s (6-8). Since then, it has become one of the most frequently identified oncogenes in human tumors, but ironically, its precise role in urothelial tumorigenesis has continued to be controversial. Although Ha-ras (as opposed to Ki-ras and $N$-ras) remains the main target of mutational activation in bladder tumors, the mutation frequency in different patient cohorts ranges from $0 \%$ to $84 \%$, with no satisfactory explanation for such a wide variation (9-12). Some studies have shown an association of the Ha-ras mutations with low-grade, noninvasive superficial papillary urothelial tumors (10), while others have suggested that the mutations play a role in bladder tumor invasion $(13,14)$; and still others found no correlation between Ha-ras mutations and tumor progression (15). Another unsettled issue is whether ras activation in the absence of activating mutations, e.g., via either overexpression of the ras gene and/or increased signaling by upstream receptor tyrosine kinases (RTKs), can lead to bladder tumorigenesis. Indeed, more than half of the human bladder tumors overexpress ras mRNA and protein $(16,17)$. In addition, several RTKs are believed to be constitutively active in human bladder tumors. Of particular interest is a recent flurry of independent studies revealing that point mutations in the FGF receptor 3 (FGFR3) gene that cause various forms of skeletal development disorders (18) occur in up to $80 \%$ of the low-grade, nonin- 

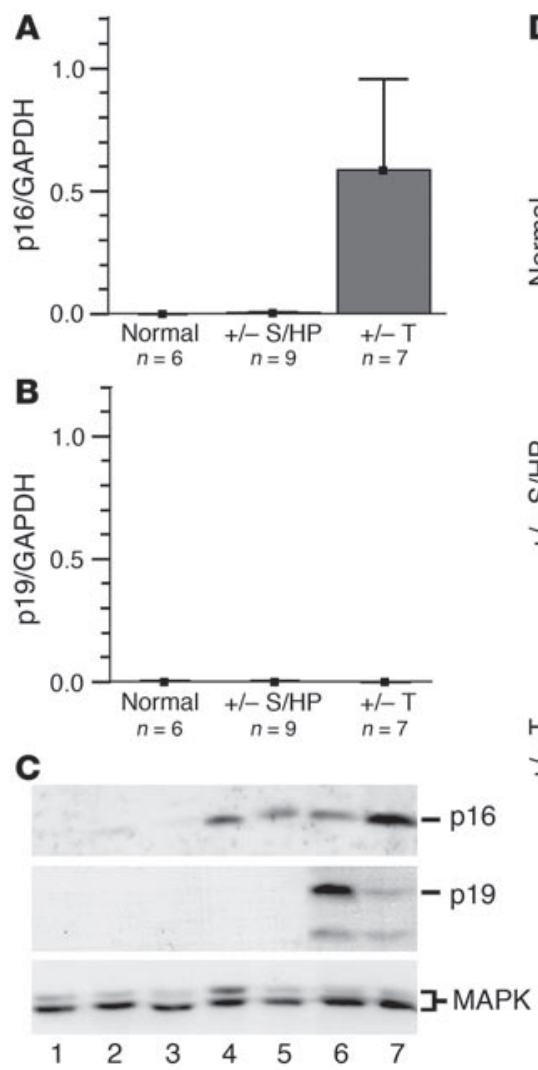

Figure 1

Expression of senescence-associated markers during urothelial hyperproliferation and tumorigenesis in UPII/Ha-ras-M-transgenic mice. (A-C) Expression of Ink4a gene products, p16Ink4a (p16) and p19Arf (p19), as assayed by real-time quantitative PCR (A and B) and Western blotting (C). $n$, number of animals assayed in each group; Normal, normal urothelia from wildtype mice; +/- S/HP, simple urothelial hyperplasia from heterozygous transgenic mice; +/- T, low-grade, noninvasive superficial papillary tumors from the heterozygous mice. The level of p16 and p19 mRNA is expressed as a ratio in reference to a simultaneously amplified internal control, GAPDH. Total urothelial proteins used for Western blotting $(\mathbf{C})$ were extracted from wild-type mice exhibiting normal urothelia (lane 1); heterozygous UPII/Ha-ras-M-transgenic mice exhibiting urothelial hyperplasia (6 months old; lanes 2 and 3 ); and heterozygous mice exhibiting low-grade, superficial papillary tumors (15 months old; lanes 4 and 5). Urothelial proteins from UPII/SV4OT-transgenic mice were used as positive controls for p16 and p19 antibodies (lanes 6 and 7). MAPK was used as a loading control. Note the marked induction of p16, but not p19, in ras-induced urothelial hyperplasia as well as in low-grade, superficial papillary tumors. (D) Histochemical detection of senescence-associated $\beta$-galactosidase activity (SA- $\beta$-gal; stained at $\mathrm{pH}$ 6.0) and lysosomal, non-senescence-associated $\beta$-galactosidase activity (adjacent sections stained at $\mathrm{pH}$ 4.0). Urothelial tissues were from wild-type mice exhibiting normal urothelium, heterozygous transgenic mice exhibiting simple urothelial hyperplasia, and transgenic mice exhibiting papillary urothelial tumors. Note the absence of senescenceassociated $\beta$-galactosidase activity in all of the urothelial lesions. Original magnification, $\times 200$.

vasive papillary bladder tumors (19-22). Together, these data suggest that ras pathway activation, whether it be via point mutation, overexpression, or upstream RTK activation, or a combination of these events, occurs in the overwhelming majority of human bladder tumors (23). However, critical experimental evidence is lacking as to whether ras activation alone is necessary and sufficient to trigger bladder tumorigenesis.

Over the past few years, we have been studying the in vivo role of ras activation in urothelial growth and proliferation by expressing a constitutively active Ha-ras under the control of a mouse uropla- ecules in urothelium in vivo; if so, whether such a compensatory induction is sufficient to halt ras-induced proliferative effects; and, more importantly, whether Ink4a deficiency can promote ras-induced bladder tumor formation.

Emerging evidence suggests that tumorigenicity of activated ras in a specific tissue also depends on the spectrum and the extent of the signaling pathways that ras exploits. The signal of activated ras is propagated mainly through 3 structurally distinct, but functionally overlapping, signaling cascades: (a) the Raf/Mek/ Erk(MAPK) cascade, which promotes cell proliferation; (b) the PI3K/AKT cascade, which mediates cell survival; and (c) the Ral 


\section{Table 1}

Expression of senescence-associated markers in activated Ha-ras-induced urothelial lesions by microarray analyses ${ }^{A}$

\begin{tabular}{lccc} 
Marker & $\mathrm{HPB}$ & $\mathrm{T} 1 \mathrm{C}$ & $\mathrm{T} 2$ \\
Ink4a $(C D K N 2 A)$ & $\mathrm{N} / \mathrm{C}^{\mathrm{D}}$ & $1 \uparrow$ & $\mathrm{N} / \mathrm{C}$ \\
Arf & $\mathrm{N} / \mathrm{C}$ & $\mathrm{N} / \mathrm{C}$ & $\mathrm{N} / \mathrm{C}$ \\
Ink4b (CDKN2B) & $\mathrm{N} / \mathrm{C}$ & $2.1 \uparrow$ & $1.9 \uparrow$ \\
$\operatorname{Dec} 1($ BHLHB2) & $\mathrm{N} / \mathrm{C}$ & $3.6 \uparrow$ & $4.0 \uparrow$ \\
DcR2 (TNFRSF10D) & $\mathrm{N} / \mathrm{C}$ & $\mathrm{N} / \mathrm{C}$ & $\mathrm{N} / \mathrm{C}$ \\
\hline
\end{tabular}

AValues shown are signal ratios (log base 2) of urothelial lesions versus normal urothelium. ${ }^{\mathrm{BHP}}$, urothelial hyperplasia pooled from the bladders of 5 independent UPII/Ha-ras-M-transgenic mice. ${ }^{\mathrm{C} T 1}$, tumor 1. ${ }^{\mathrm{DN}} / \mathrm{C}$, no change. $\uparrow$ denotes overexpression.

guanine nucleotide exchange factor (RalGEF)/Ral family GTPase, which was recently shown to be important for transformation and tumorigenesis $(38,39)$. Thus far, there is virtually no information about whether ras-mediated urothelial tumor initiation requires the preferential activation of one, a combination, or all of the effector pathways. It is also not known whether ras downstream effectors can crosstalk with other signals such as the STAT pathway, whose activation is indispensable for tumorigenesis (40). Last, it is unclear whether the level and spectrum of downstream signal activation are dependent on the strength or level of ras activation.

In this study, we examine the biological responses of in vivo urothelial cells to ras activation; the role of Ink $4 a / A r f$ gene in suppressing urothelial proliferation; the effect of increasing the dosage of activated Ha-ras on urothelial tumorigenesis; and the signaling effectors that are required to initiate urothelial tumors. Our data indicate that it is the hyperactivation of ras-signaling pathways, but not the lack of Ink $4 a / A r f$, that triggers urothelial tumor formation along a low-grade, noninvasive papillary pathway. These data highlight the critical importance of the effects of quantitative changes on oncogene activation in defining the oncogene potency. They also shed light on the molecular effectors involved in the earliest stages of urothelial tumorigenesis and suggest that selectively inhibiting ras downstream effectors may be of therapeutic value in treating and preventing the recurrence of low-grade, noninvasive papillary bladder tumors, the most common form of tumors in the urinary tract.

\section{Results}

Ha-ras activation in urothelium selectively induced senescence-associated molecules without histological evidence of senescence. Enforced expression of activated Ha-ras in primary cultured fibroblasts often triggers an upregulation of prosenescence molecules, the most prominent of which are tumor suppressors p16Ink4a and p19Arf $(27,41)$. These molecules play critical roles in provoking premature cellular senescence in vitro, although little is known about whether such an effect occurs in urothelial cells in vivo and, if so, whether it leads to cellular senescence. By analyzing a transgenic mouse model that specifically expresses a constitutively active $\mathrm{Ha}$-ras oncogene in the urothelium, we found that simple urothelial hyperplasia was associated with a slight increase in expression of p16Ink4a and that late-onset low-grade, noninvasive papillary bladder tumors were associated with a marked increase in expression of p16Ink4a, on RNA as well as protein levels (Figure 1, A and C). In contrast, p19Arf was completely unaffected in these lesions (Figure 1, B and C).
DNA microarray analyses not only provided consistent results, but identified several additional senescence-associated markers that were recently described in transgenic mice expressing an activated Ki-ras in lung epithelial cells $(2,28)$. Thus, Ink $4 b$ (also named CDKN2B) and Dec1 (also named BHLHB2) were strongly induced in the low-grade, noninvasive papillary bladder tumors (Table 1). No increase in expression was observed, however, with another marker, DcR2 (or TNFRSF10D), in simple urothelial hyperplasia or tumors (Table 1 ) or with ras-induced senescence 1 molecule (RIS1; ref. 42; data not shown). Despite the significant upregulation of several senescence-associated molecules, histological evidence of cellular senescence was not observed in Ha-ras-expressing urothelial cells, as indicated by the lack of enzyme activity of senescence-associated $\beta$-galactosidase in any of the urothelial lesions examined (Figure 1D; ref. 43). Therefore, it appears that both the spectrum of affected senescence-associated molecules and the biological consequences of ras activation are cell type dependent. Nevertheless, the increase in the expression of certain prosenescence molecules may represent an induction of compensatory mechanisms employed by the urothelial cells in response to Ha-ras activation in order to curtail cell growth and proliferation.

Ink4a/Arfdeficiency failed to cooperate with Ha-ras activation in initiating urothelial tumors. Because p16Ink4a induction by an activated Ha-ras may represent a tumor-inhibiting, host-defense mechanism, we hypothesized that Ink4a/Arf deficiency, which occurs frequently in human urothelial hyperplasias (44), might accelerate ras-induced urothelial tumorigenesis. To test this hypothesis, we crossed transgenic mice expressing a constitutively active Ha-ras mutant under the control of the UPII promoter (UPII/Ha-ras-M mice) with the Ink4a/Arf-knockout mice (Figure 2A). Consistent with our previous observations, UPII/Ha-ras-M-transgenic mice developed simple urothelial hyperplasia (Figure 2B; ref. 24). Ink4a/ Arf-knockout mice exhibited normal urothelia up to 8-11 months of age (Figure $2 \mathrm{~B}$ and Table 2), at which point the mice developed fatal melanomas and soft-tissue sarcomas (data not shown) that prevented further observation (45). Surprisingly, mice transgenic for the UPII/Ha-ras-M that were also heterozygous or nullizygous for the Ink4a/Arf gene (Figure 2B and Table 2) exhibited only simple urothelial hyperplasia, without developing any full-fledged urothelial tumors. Thus, Ink4a/Arf deficiency did not affect tumor latency in urothelia expressing an activated Ha-ras and did not cooperate with Ha-ras activation to initiate urothelial tumor formation. Due to the lethality of the Ink $4 a / A r f$ knockout, it remains unclear whether Ink4a/Arf deficiency might promote muscle invasion of ras-induced tumors at older ages (>11 months).

High-level expression of activated Ha-ras per se was sufficient to induce rapid urothelial tumorigenesis. While Ink $4 a / A r f$ deficiency failed to accelerate urothelial tumorigenesis in transgenic mice expressing an activated Ha-ras, simply doubling the transgene dosage of the activated Ha-ras by converting the heterozygous UPII/Ha-ras-M mice into homozygous ones (Figure 3A), which roughly doubled the mRNA and protein levels of the mutant Ha-ras (Figure 3, B-D), resulted in early-onset and rapidly growing bladder tumors. The tumors arose as early as 2 months, and by 6 months, all homozygous mice had developed full-blown bladder tumors (Figure 3F). This exceedingly short latency was in striking contrast to the long latency seen in the heterozygous mice, in which the great majority of tumors occurred after 18 months of age. In spite of the difference in tumor latency, tumors in both heterozygous and homozygous mice were consistently of low histological grade and were super- 

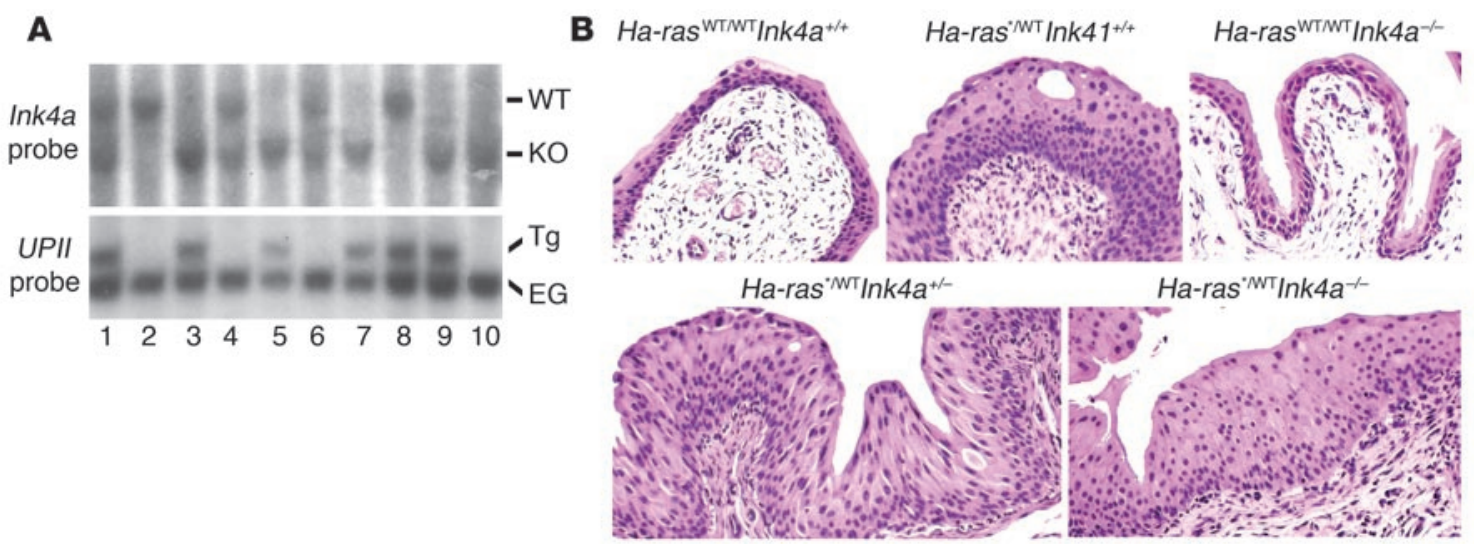

\section{Figure 2}

Analysis of synergism between Ha-ras activation and Ink4a/Arf deficiency. (A) Southern blot analysis of a representative transgenic mouse litter derived from intercrossing and backcrossing between UPII/Ha-ras-M transgenics and Ink4a/Arf knockouts. Upper panel: analysis of the Ink4a/Arf alleles (WT allele: 9.2-kb; KO allele: $6.0 \mathrm{~kb}$ ). Lower panel: analysis of the UPII/Ha-ras-M allele (Tg: 1.7-kb; endogenous UPII gene [EG]: $1.4 \mathrm{~kb})$. Mice of several genotypes were obtained, including mice wild-type for both genes (lane 2); mice heterozygous for the ras mutant allele alone (lane 8); mice heterozygous for the Ink4a/Arf allele alone (lanes 4 and 6); mice homozygous for the Ink4a/Arf-knockout allele alone (lane 10); mice heterozygous for the ras mutant allele and heterozygous for the Ink4a/Arf allele (lane 1); and mice heterozygous for the ras mutant and homozygous for the Ink4a/Arf-knockout allele (lanes 3, 5, 7, and 9). (B) Histopathology of urinary bladders from a wild-type mouse showing normal morphology; a ras-transgenic mouse (11 months) showing simple urothelial hyperplasia; an age-matched Ink4a/Arf-knockout mouse showing normal morphology; a mouse heterozygous for both ras mutant allele and Ink4a/Arf allele showing simple urothelial hyperplasia; and a mouse heterozygous for the ras mutant and nullizygous for the Ink4a/Arf allele also showing simple urothelial hyperplasia. Note that deficiency of Ink4a/Arf failed to accelerate ras-induced urothelial tumor formation. *WT denotes mice heterozygous for the Ha-ras mutant. Original magnification, $\times 200$.

ficial papillary in nature (Figure 3G). Tumors of the homozygous mice were more cellular (Figure 3G, lower right), perhaps reflecting a higher degree of cell proliferation. The fact that p16Ink4a levels remained high in tumors of the homozygous mice (Figure $3 \mathrm{E}$ ) further supports the idea that $\mathrm{p} 16 \mathrm{Ink} 4 \mathrm{a}$ deficiency is not required for urothelial tumor initiation.

Systematic dissection of the urinary bladders from hetero- and homozygous mice between 1 and 6 months of age revealed the sequential steps of urothelial proliferation and tumor formation. Heterozygous mice exhibited normal-appearing bladder epithelium at 1-2 months, after which they developed simple urothelial hyperplasia that persisted during the entire observation period (Figure 4A, top row). By contrast, homozygous mice developed marked urothelial hyperplasia at 1 month, which quickly evolved to nodular hyperplasia between 2 and 3 months. Distinct from the simple hyperplasia, the nodular hyperplasia had acquired features of neovasculization and rudimentary fibrovascular cores, presumably serving to nourish the overlaying proliferating urothelial cells. The emergence of these mesenchymal components appeared to be critical for setting the stage for urothelial tumor initiation (see below). By 4 months, most homozygous mice (approximately 70\%) had already developed full-blown bladder tumors, which further increased in volume between 5 and 6 months (Figure 4A, bottom row). Another striking feature was that tumors in homozygous mice were invariably multifocal and papillary, with multiple fibrovascular stalks projecting from the bladder wall toward the bladder lumen. Not only were tumors found in the bladders, they were also observed consistently in the renal pelvis and ureters (Figure 4B, bottom row), which like bladder are lined by the urothelium and hence expressed the activated Ha-ras. It is worth noting that these upper-tract tumors were never observed in heterozygous mice before 12 months of age (Figure $4 \mathrm{~B}$, top row; and data not shown). Establishment of a homozygous line was unsuccessful because the homozygous mice were infertile; the reason for their infertility remains to be elucidated. Most homozygous mice succumbed to obstructive nephropathy (data not shown) around 6 months of age, produced by multiple urothelial tumors throughout the urinary tract. While the urothelial tumors in homozygous mice were extremely rapid-growing, they remained at low pathological grades and were confined to the urothelial layer without invading the lamina propria. These results established that quantitative differences in the expression level of activated Ha-ras plays a crucial role in determining the time course of urothelial tumor development and that high-level expression of an activated Ha-ras is sufficient to induce urothelial tumorigenesis along the low-grade, noninvasive phenotypic pathway.
Table 2

Urothelial abnormalities in compound mice

\begin{tabular}{|c|c|c|c|c|}
\hline \multirow[b]{2}{*}{ Urothelial phenotype } & \multicolumn{4}{|c|}{ Genotype $^{A}$} \\
\hline & $\begin{array}{c}\text { Ha-ras }^{* / \mathrm{WT}} / n k 4 \mathrm{a}^{+/+} \\
(n=12)\end{array}$ & $\begin{array}{c}\text { Ha-ras }{ }^{\mathrm{WT} / \mathrm{WT}} / n_{k 4 a^{-/}-} \\
(n=10)\end{array}$ & $\begin{array}{c}\text { Ha-ras }^{\star / \mathrm{WT}} / n k 4 a^{+/-} \\
(n=9)\end{array}$ & $\begin{array}{c}\text { Ha-ras }{ }^{\star / \mathrm{WT}} / n k 4 a^{-1-} \\
\quad(n=10)\end{array}$ \\
\hline Normal & 0 & 10 & 0 & 0 \\
\hline Hyperplasia & 11 & 0 & 9 & 10 \\
\hline Tumor & 1 & 0 & 0 & 0 \\
\hline
\end{tabular}

AUrinary bladders of compound mice (8-11 months) were examined histopathologically. $n$, total number of animals analyzed. */WT denotes mice heterozygous for the Ha-ras mutant. 
A

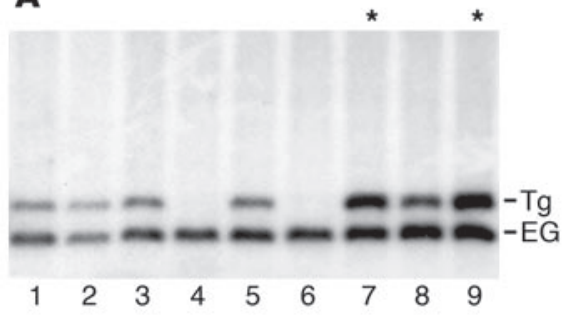

D

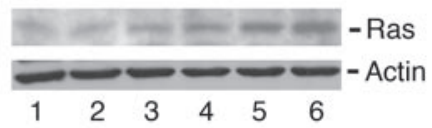

E

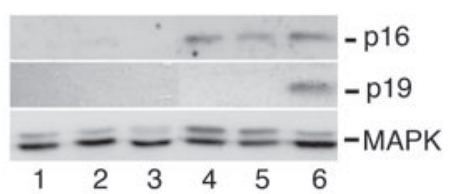

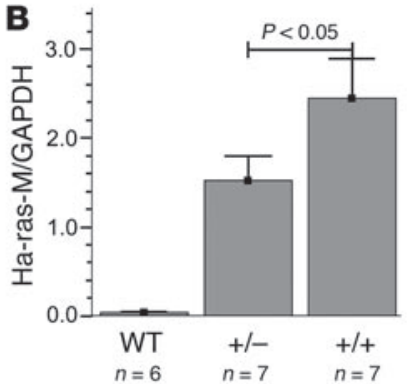

$\mathbf{F}$

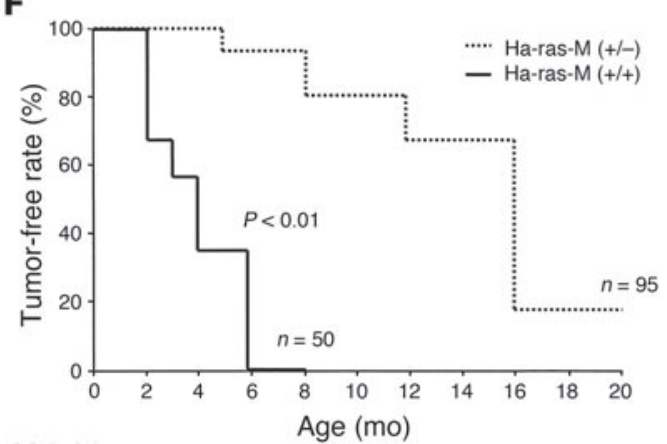

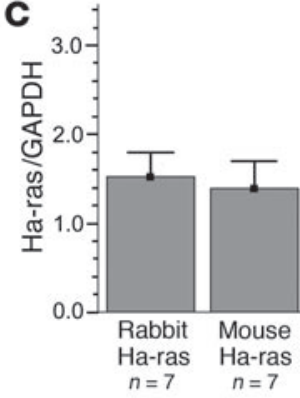

$n=7$

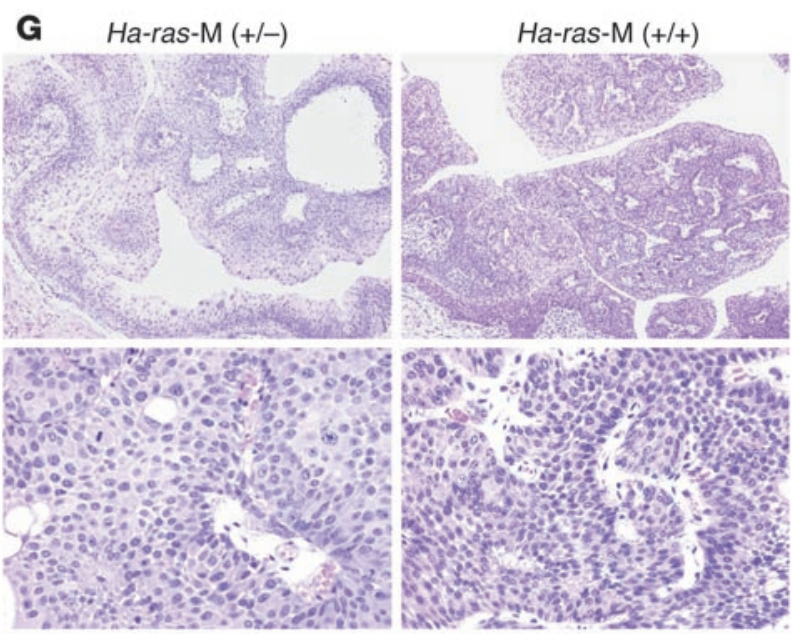

\section{Figure 3}

The effect of gene dosage of activated Ha-ras on urothelial tumorigenesis. (A) Genotyping by Southern blotting of mice derived from intercrossing of heterozygous mice, showing wild-type mice with the endogenous UPII fragment (lanes 4 and 6), heterozygous mice with Tg/EG ratio of about 1:2 (lanes 1-3, 5, and 8), and homozygous mice with $\mathrm{Tg} / \mathrm{EG}$ ratio of about 1:1 (lanes 7 and 9). (B) Real-time RT-PCR quantification of activated Ha-ras expression in urothelia of $\mathrm{Tg}$ mice, showing that homozygous (+/+) mice expressed nearly twice as much as heterozygous (+/-) mice. The expression level was calculated as ratio in reference to a simultaneously amplified internal GAPDH control. $n$, number of animals assayed. Bars denote SD. (C) Quantification by real-time PCR of the expression of the transgene-encoded rabbit Ha-ras and the endogenous mouse Ha-ras in heterozygous mice. Note that the levels of expression were roughly equal. (D) Western blot analysis of ras proteins of the wild-type mice (lanes 1 and 2) and heterozygous (lanes 3 and 4) and homozygous (lanes 5 and 6) UPII/Ha-ras-M-transgenic mice. (E) Western blot analysis of p16Ink4a and p19Arf expression in age-matched (6 months) wild-type (lane 1), heterozygous (lanes 2 and 3 ), and homozygous (lanes 4 and 5) UPII/Ha-ras-M-transgenic mice. Urothelial proteins from UPII/SV40T-transgenic mice were used as positive control (lane 6). (F) Comparison of the tumor-free rate in hetero- or homozygous mice. (G) Morphology of bladder tumors from heterozygotes and homozygotes. Original magnification, top row, $\times 50$; bottom row, $\times 200$.

Coactivation of AKT and STAT pathways during urothelial nodular byperplasia and tumor formation. To determine the molecular effectors whereby Ha-ras leads to urothelial tumorigenesis, we compared the level and activation status of several major signaling molecules that act downstream of ras between age-matched hetero- and homozygous mice. Normal urothelium of wild-type mice expressed MAPK, but mostly as the inactive (underphosphorylated) form (Figure 5, A and B, upper panels). This is consistent with results of previous studies using tritium thymidine labeling indicating that most urothelial cells are in a quiescent state under normal conditions (46). Ha-ras activation in urothelia did not upregulate MAPK but markedly increased its phosphorylation, hence its activity in both hetero- and homozygous mice (Figure $5 \mathrm{~A})$. Some of the phosphorylated MAPK appeared to have translocated into the nuclei (Figure 5B, middle panel). Thus, MAPK activation is important for urothelial proliferation but is insufficient 
A
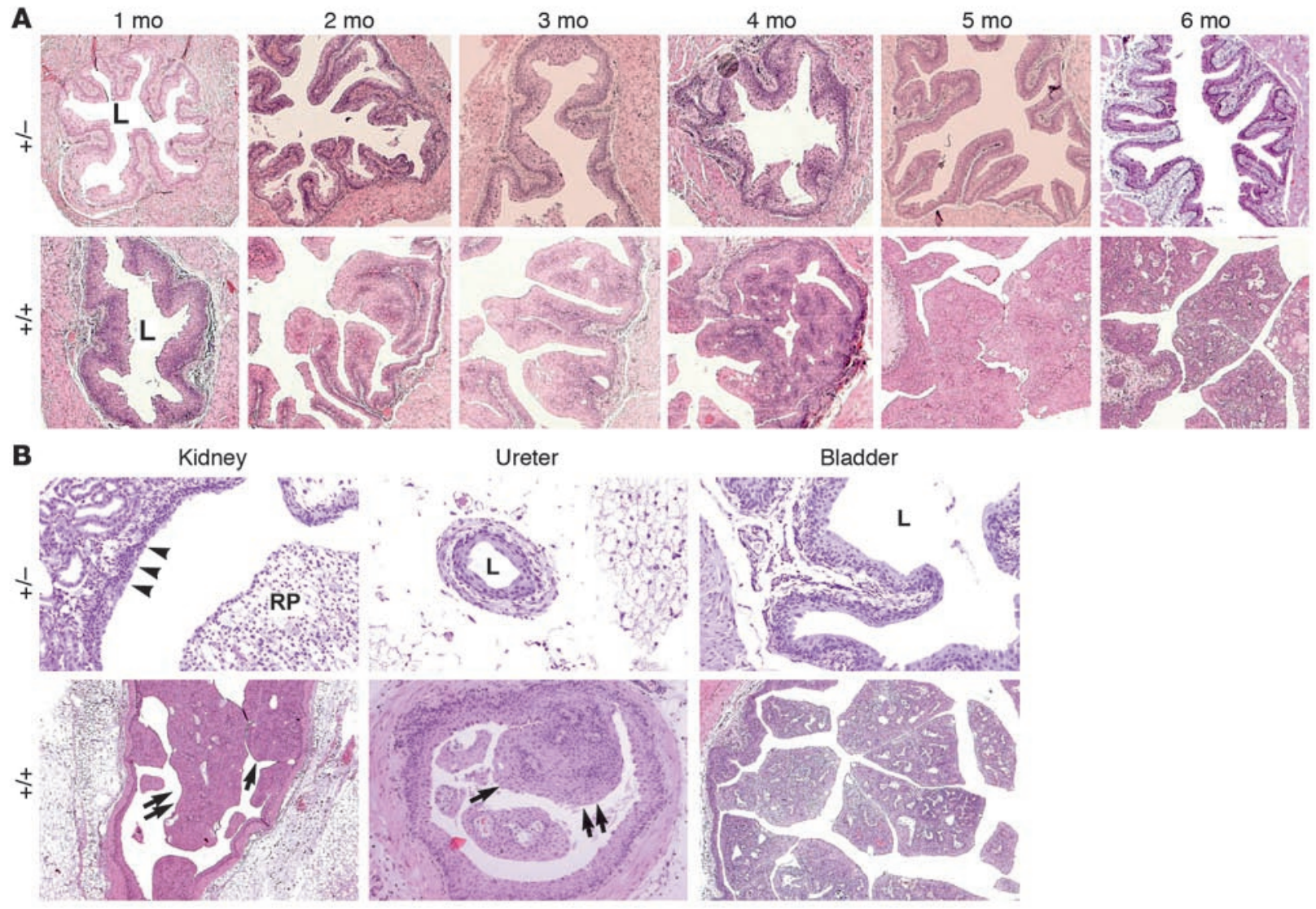

\section{Figure 4}

Sequence of urothelial tumorigenesis in heterozygous and homozygous ras transgenics $(\mathbf{A})$ and tumorigenesis in different parts of the urinary tract (B). (A) Urinary bladders from 1- to 6-month-old heterozygous (top row) and homozygous (bottom row) mice were assessed for histopathological changes, and representative images are shown. Whereas heterozygous mice showed simple urothelial hyperplasia with no frank tumors throughout this time period, homozygous mice showed marked hyperplasia at 1 month, nodular and papillary hyperplasia at 2-3 months, and urothelial tumors as early as 3-4 months, with significant increase in volume at 5-6 months. Original magnification, $\times 50$. (B) The renal pelvis (arrowheads), ureter, and bladder urothelia of a 6-month-old heterozygous mouse all exhibited hyperplastic urothelial changes, while an agematched homozygous mouse developed papillary tumors (arrows) not only in the bladder, but also in the renal pelvis and ureter. L, lumen; RP, renal papilla. Original magnification, $\times 200$ for all panels except the lower-right panel $(\times 50)$.

to induce urothelial tumor formation. Profound differences were observed, however, in AKT expression and phosphorylation status between hetero- and homozygous animals. Increased expression of AKT, accompanied by increased phosphorylation of both Thr308 and Ser473, was seen primarily in the homozygous mice with nodular hyperplasia and papillary tumors (Figure 5A), with the phosphorylated form of Ser473 prominently detected in bladder tumors of the homozygous mice (Figure 5B, bottom row). In accordance with AKT activation, major downstream components of the AKT pathway, including glycogen synthase kinase $3 \beta$ (GSK3B) and forkhead transcription factor forkhead in human rhabdomyosarcoma (FKHR), were preferentially activated in nodular hyperplasia and tumors from the homozygous mice (Figure 5A). These results strongly suggest a critical role for PI3K/AKT pathway activation in urothelial tumor initiation.

Because of the potential crosstalk between ras effectors and other signaling cascades, and because of the critical importance of the STAT pathway, particularly STAT3 and STAT5, in tumor cell/matrix crosstalk prior to and during tumorigenesis (40), we examined the activation status of these molecules during urothe- lial tumorigenesis. An intense upregulation of STAT3 and markedly increased phosphorylation - the latter of which has been shown to facilitate STAT3 tetramerization, nuclear translocation, and increased target transcription - were observed only in the homozygous mice (Figure 6, A and B, top row). While the level of STAT5 remained relatively constant in the transgenic mice, regardless of the zygosity, phosphorylation of the molecule was also seen primarily in the homozygous mice (Figure 6A). The activation of STAT3/5 in the homozygous mice paralleled a marked induction of VEGF and the appearance of a fibrovascular core inside the proliferative urothelial cells (Figure 6B, bottom row), suggesting a role for the stromal cells in activating the STAT pathway. Together, these data indicate that both AKT and STAT signaling occurs only when Ha-ras is hyperactivated and is strongly associated with nodular urothelial hyperplasia and tumor formation.

Phosphorylation of the C terminus of phosphatase and tensin bomolog coincided with AKT and STAT activation. Since phosphatase and tensin homolog (PTEN) is a key negative regulator of AKT and STAT (47-49), we examined whether overactivation of these molecules could be attributed, at least in part, to the inactivation of PTEN 


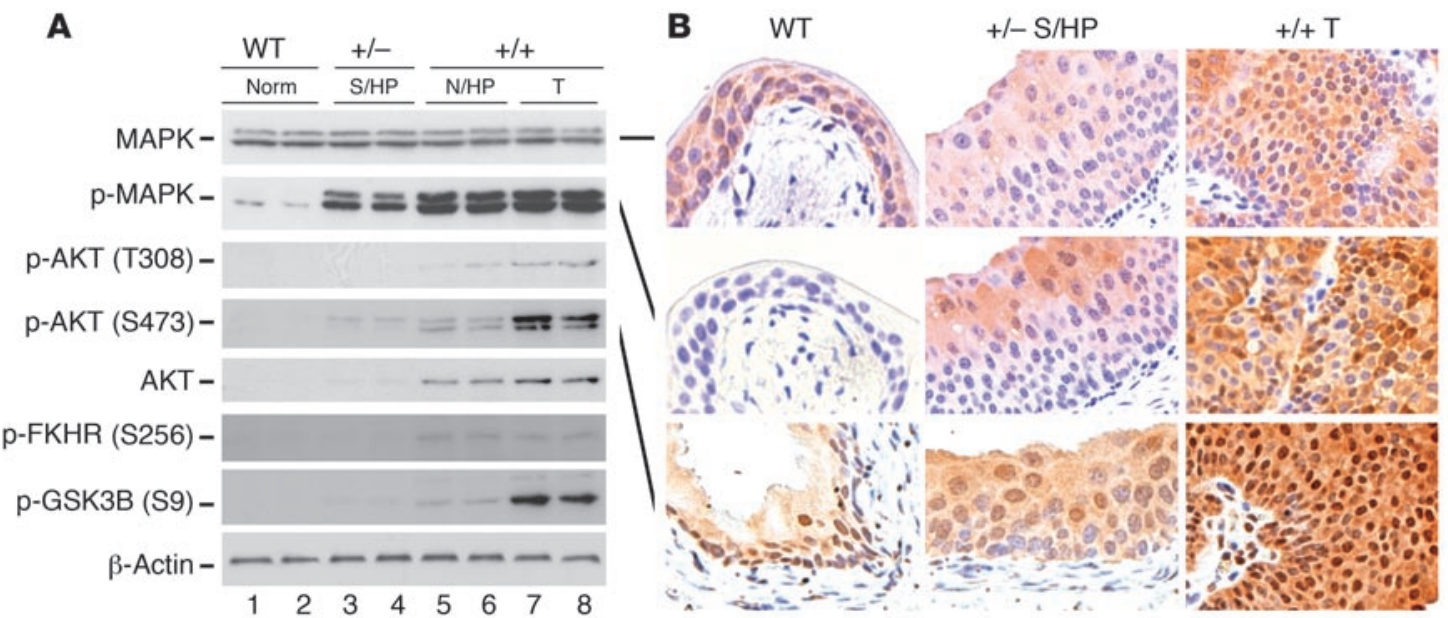

\section{Figure 5}

Activation of MAPK and AKT pathway effectors during urothelial tumorigenesis. (A) Total urothelial proteins (50 $\mu$ g/lane) from wild-type mice (lanes 1 and 2), heterozygous Ha-ras-transgenic mice (6 months old) exhibiting simple urothelial hyperplasia (lanes 3 and 4 ), homozygous transgenic mice (2-3 months old) exhibiting nodular urothelial hyperplasia (N/HP) (lanes 5 and 6), and homozygous mice (5-6 months old) exhibiting lowgrade superficial urothelial tumors (T; lanes 7 and 8 ) were resolved by SDS-PAGE, transferred onto PVDF membrane, and blotted with antibodies against nonphosphorylated and phosphorylated forms of MAPK, AKT, and phosphorylated downstream targets of AKT (FKHR and GSK3B). $\beta$-Actin was used as a loading control. Note the strong activation of the AKT pathway predominantly in the homozygous mice (lanes 5-8). (B) Immunohistochemical detection of MAPK (upper panel), phosphorylated MAPK (middle panel), and phosphorylated AKT (Ser473; lower panel) in normal urothelium (WT); simple urothelial hyperplasia of the heterozygous mice; and low-grade superficial papillary tumors of the homozygous mice. Note the intense nuclear labeling of phosphorylated AKT in the bladder tumor of the homozygous mice. Original magnification, $\times 200$.

via the hyperphosphorylation of its $\mathrm{C}$ terminus - an event known to functionally inactivate this protein $(50,51)$. Unlike p16Ink4a, which was induced by Ha-ras activation, PTEN levels remained relatively constant before and after ras activation (Figure 6A). However, this protein was heavily phosphorylated at the C-terminal Ser380, most profoundly in homozygous mice (Figure 6, A and B, middle row). The result raised the interesting possibility that one of mechanisms that allows ras hyperactivation of AKT and STAT to proceed is the functional disabling of the upstream inhibitor PTEN by hyperphosphorylation of its $\mathrm{C}$ terminus.

\section{Discussion}

Ink4a/Arf is not a cooperative partner of Ha-ras in urothelial tumor initiation. A surprising finding of the present study is the apparent lack of synergism between activated Ha-ras and Ink $4 a / A r f$ deficiency in urothelial tumorigenesis. The germline loss of one, or even both, alleles of the Ink $4 a /$ Arf gene failed to accelerate urothelial tumor formation in mice expressing a constitutively active Ha-ras in the urothelium (Figure 2). This result stands in stark contrast to the demonstrated synergism between these 2 genetic events in other cell types, including melanocytes, astrocytes, and lung and pancreatic epithelial cells $(31-33,52)$. Our result does not support the idea that since deletion of the Ink $4 a / A r f$ locus occurs frequently in the precancerous lesions of the bladder, it must be invariably involved in urothelial tumor initiation (53). However, our result does support the important concept that not only the tumorigenicity of an oncogene but also its cooperative tumor suppressor partner can be cell type specific (3). Precisely why activated Ha-ras and Ink4a/Arf deficiency are not synergistic in the urothelium is presently unclear, but the following scenarios could be involved. First, the activated Ha-ras may require a cooperative partner other than Ink4a/Arf. For example, it cannot be ruled out that the dele- tion of the 9p21 locus, where Ink4a/Arf resides, actually reflects more of a loss of the adjacent Ink $4 b$ gene rather than of the Ink $4 a /$ Arf gene per se. Ink $4 b$ encodes a CDK inhibitor that is critical in negatively regulating $\mathrm{G}_{1} / \mathrm{S}$-phase transition. Although it has not been as well studied as the Ink $4 a$ gene, there was reduced expression of the $15 \operatorname{Ink} 4 \mathrm{~b}$ product in one cohort, occurring in as many as $66 \%$ of early-stage bladder tumors (54). In our study, we observed a robust increase in expression of the Ink $4 b$ gene in response to Ha-ras even in the hyperplastic phase of urothelial proliferation (Table 1), suggesting that the loss of Ink $4 \mathrm{~b}$ might cooperate with Ha-ras activation in accelerating urothelial tumorigenesis. It would be interesting to test this hypothesis by crossing the Ink $4 b$ knockouts with the ras transgenics. Other collaborative partners of Ha-ras may also play a urothelium-specific role. For instance, we recently demonstrated that the loss of p53 significantly shortened the latency of ras-induced urothelial tumors, converting urothelial hyperplasia to full-fledged bladder tumors (55). The fact that p19Arf acts in the p53 pathway but failed to exert the same effect during Ink4a/Arf deficiency (Figure 2 and Table 2) as does p53 raises the possibility that the biological effects resulting from the deficiency of these 2 tumor suppressor genes are not equivalent.

Second, as far as the "partnership" is concerned, it is also possible that, in urothelium, Ink4a/Arf deficiency requires the cooperation of an oncogene other than Ha-ras for tumor initiation. However, even if this were the case, it would only account for a minority of the early-stage bladder tumors, because an overwhelming majority of the early-stage tumors in humans have ras pathway activation in one form or another (see below). Third, while Ink4a/ Arf deficiency does not appear to be involved in bladder tumor initiation, it remains possible that it could cooperate with activated Ha-ras or another genetic event at later stages to promote bladder tumor progression. We attempted to test this hypothesis 
A

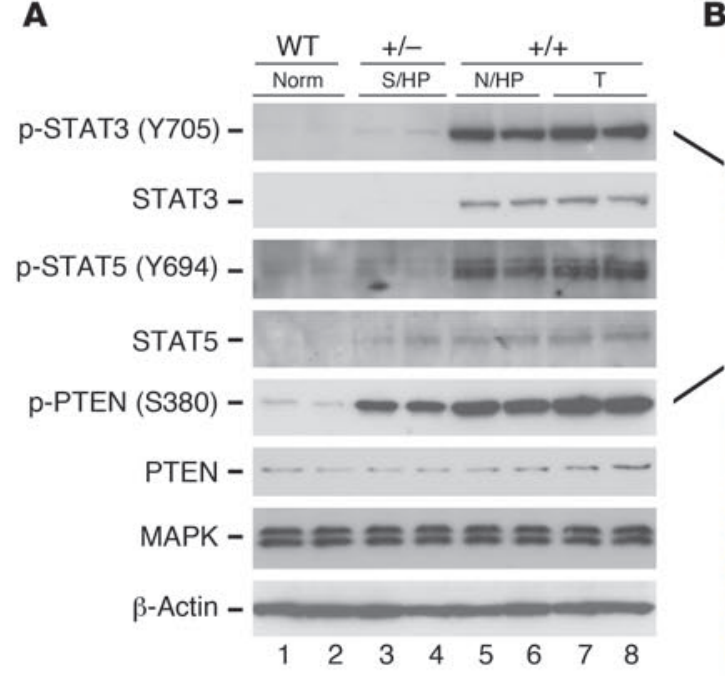

B
WT

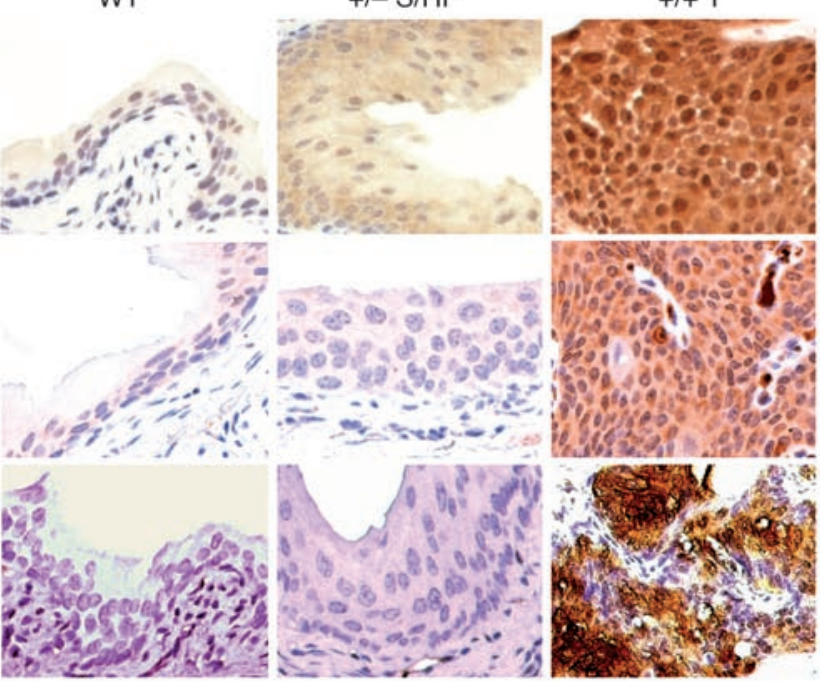

\section{Figure 6}

Activation of STAT3 and STAT5 and inactivation of PTEN during urothelial tumorigenesis. (A) Normal urothelia and urothelial lesions indicated in Figure 5 were subjected to Western blot analysis using antibodies against nonphosphorylated and phosphorylated STAT3, STAT5, and PTEN. MAPK and $\beta$-actin were used as loading controls. Note the pronounced induction and activation of both STAT3 and STAT5 in homozygous mice exhibiting nodular hyperplasia and low-grade superficial papillary tumors (lanes 5-8). Also note the strong, C-terminal phosphorylation of PTEN, an event known to functionally inactivate its phosphatase activity, in the transgenic mice (lanes 3-8), particularly in the homozygous mice (lanes 5-8). (B) Immunohistochemical localization of phosphorylated STAT3 (top row), C-terminally phosphorylated PTEN (middle row) and VEGF (bottom row) in normal urothelium (WT), simple urothelial hyperplasia of the heterozygous mice, and low-grade superficial papillary tumors of the homozygous mice. Note the strong nuclear labeling of phosphorylated STAT3, cytoplasmic staining of C-terminally phosphorylated PTEN, as well as VEGF induction predominantly in the urothelial tumors of the homozygous mice. Original magnification, $\times 200$.

by generating compound mice homozygous for activated Ha-ras and nullizygous for Ink4a/Arf; this approach failed, however, due to the infertility of the ras-homozygous mice (data not shown). Finally, Ink4a/Arf deficiency could be involved in a tumorigenic pathway that is distinct from the one involving the activated Ha-ras. It has been well established that human urothelial tumors are a mixture of biologically, phenotypically, and genetically different entities $(23,56-58)$. It is possible then that Ink4a/Arf and $H a$-ras can act separately in divergent pathways of urothelial tumorigenesis. Definitive answers to these unresolved issues will come from further experimental analyses using both animal models and human tumor specimens.

Tumorigenicity of Ha-ras: critical role of quantitative differences. We were also surprised by the finding that doubling the gene dosage of the activated Ha-ras in the ras-homozygous background, even in the presence of the wild-type Ink $4 a$ gene, triggered early-onset, rapidly growing, and fully penetrant urothelial tumors throughout the urinary tract (Figures 3 and 4). This finding strongly suggests that while the low-level expression of a constitutively active Ha-ras is insufficient, even in collaboration with Ink4a/Arf deficiency, to initiate urothelial tumors, overexpression of the constitutively active Ha-ras is both necessary and sufficient to initiate urothelial tumor formation. These results highlight an important mechanism of Ha-ras activation that has not been fully appreciated to date and underscore the importance of evaluating not only structural but also quantitative aspects of Ha-ras activation when assessing the tumorigenic potential of activated Ha-ras oncogene.

Evidence is accumulating that overactivation of Ha-ras occurs in human urothelial tumors. Thus, findings reported here are relevant to human urothelial tumorigenesis as well. Czerniak et al. showed that mutation and overexpression of Ha-ras occurred concurrently in about $10 \%$ of the bladder tumors by means of alterative splicing of the last intron of the mutated Ha-ras gene $(11,59)$. Another mechanism may involve transcriptional upregulation of the mutated Ha-ras gene, as suggested by several independent studies that show that more than half of all human bladder tumors overexpress the ras gene $(16,17)$. Based on a conservative estimate that $30 \%-40 \%$ of the bladder tumors harbor Ha-ras mutations (59), there is reason to believe that ras mutation and overexpression overlap in a significant number of cases. Furthermore, activation of the ras pathway, via upstream-acting RTKs, such as FGFR3, EGFR, and Erb family proteins, are extremely prevalent in human bladder tumors (19-22). It is highly likely that these RTKs can functionally overactivate the ras pathway in the presence or absence of ras mutations.

Whether the enhanced tumorigenicity from overexpression of an activated Ha-ras applies to other oncogenes is currently unknown, but it has been documented that amplification and/or overexpression of oncogenes are common features of many human tumors (4). Hence, it seems likely that what we have learned here about the gene-dosage dependence of oncogene activation is not limited to Ha-ras but can be extended to other oncogenes. Further experimental studies are needed to investigate this idea.

The mechanism whereby overactivated Ha-ras transforms the urothelium may lie in the imbalance of positive and negative pressures exerted on cell-cycle progression. Under this paradigm, either the increase in positive forces or the decrease in negative forces could tilt the balance toward cell-cycle progression. This concept has been proven valid with tumor suppressors, in which reduced gene dosage per se, via the loss of 1 tumor suppressor gene allele 


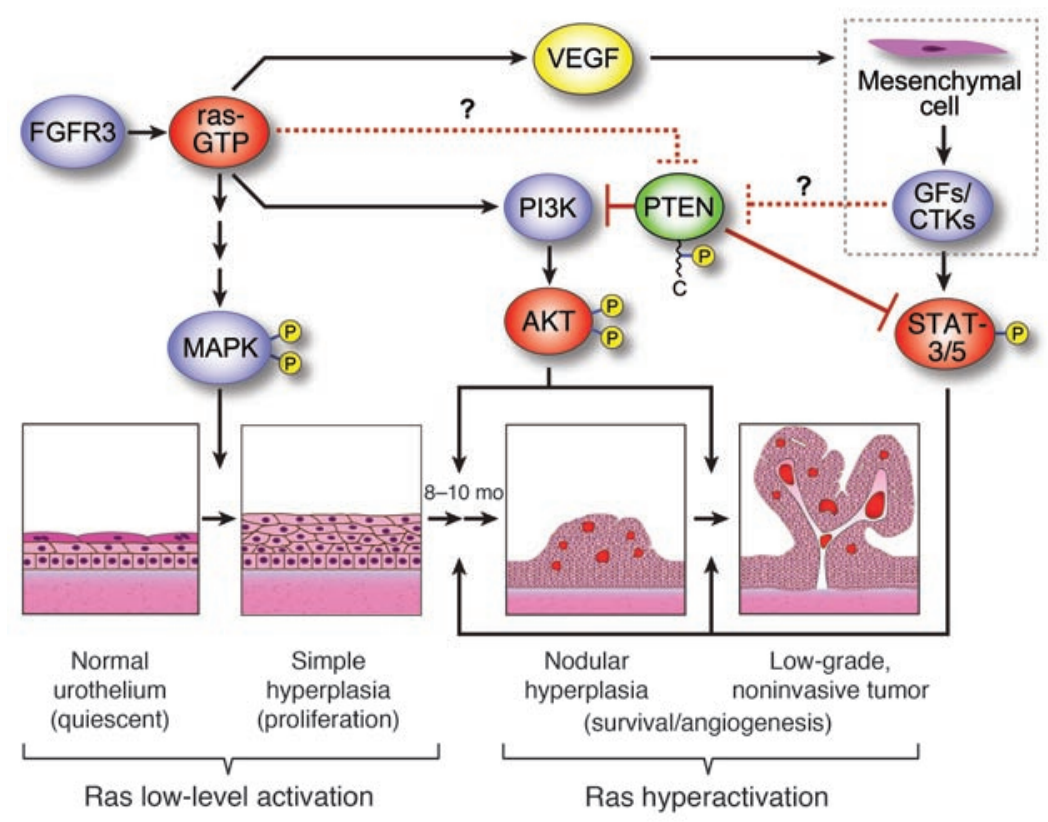

Figure 7

Schematic diagram of signaling effectors underlying the genesis of low-grade, noninvasive papillary urothelial tumors. Low-level expression of a constitutively active rasGTPase (ras-GTP) activates the MAPK pathway and converts quiescent normal urothelial cells into simple urothelial hyperplasia, which is persistent for an extended period (8-10 months) without progressing to urothelial tumors. In contrast, overactivation of the ras-GTPase profoundly activates survival and angiogenesis signals along PI3K/ AKT and STAT pathways, leading to the formation of nodular hyperplasia and lowgrade, noninvasive urothelial tumors. The activation of the STAT pathway that is unique to nodular hyperplasia and urothelial tumors, both of which contain mesenchymal components, may result from signaling from growth factors (GFs) and cytokines (CTKs) produced by the tumor mesenchyme. The activation of AKT and STAT pathways may also be facilitated by the functional inactivation of their upstream inhibitor, PTEN, via its C-terminal hyperphosphorylation. FGFR3 mutations, which occur in up to $80 \%$ of low-grade, noninvasive human bladder tumors, are likely to transmit the signals along pathways similar to those described above. C, carboxyl terminus.

(haploinsufficiency), enhances tumorigenesis (60). As for the Ha-ras oncogene, at low expression levels, its mitogenic effects may be counterbalanced by the antiproliferative forces, such as prosenescence and tumor-suppressing molecules (Figure 1 and Table 1). Consequently, cell cycle regains control, with no tumor formation. In many cases, a cooperative effect, such as the inactivation of a tumor-suppressor gene, is required for Ha-ras to be fully transforming. However, as we showed here, when Ha-ras is overactivated, it may be able to override the antagonistic effects of induced tumor-suppressor genes, resulting in tumorigenesis without the need for a cooperative event. This explanation is completely in line with the paradigm of cell-cycle control and tumorigenesis.

Ras activation causes urothelial tumorigenesis along the low-grade, noninvasive papillary pathway. Unlike most epithelial tumors that follow a single path of evolution from benign to malignant stages, urothelial tumors manifest themselves as at least 2 drastically different diseases $(22,56-59,61)$. The low-grade, noninvasive papillary tumors, accounting for $70 \%-80 \%$ of all clinical cases, are often multifocal in the bladder and tend to recur, but they rarely advance to the muscle-invasive and metastatic stages. On the other hand, the muscle-invasive tumors almost invariably follow an aggressive clinical course, with more than $50 \%$ of tumors eventually metas- tasizing to distant organs, despite the complete surgical removal of the bladder. There is compelling evidence from clinicopathological and longitudinal studies that most muscle-invasive tumors are not derived from the low-grade, noninvasive papillary tumors. Rather, they seem to arise de novo or are derived from high-grade, flat, carcinoma-in-situ lesions. Genetic studies of muscle-invasive bladder tumors from humans suggest that more than half of these lesions harbor structural and functional defects in the components of $\mathrm{p} 53$ and/or Rb pathways $(62,63)$. Therefore, the current consensus is that these $\mathrm{p} 53 / \mathrm{Rb}$ defects may underlie urothelial tumor development along the invasive pathway. By contrast, the genetic defect(s) that drive urothelial tumor formation along the low-grade, noninvasive pathway have been long sought after, with little success, due partly to the controversy surrounding the role of Ha-ras activation. In this study, we demonstrated that hyperactivation of Ha-ras induced urothelial tumors that were consistently of low pathological grade, papillary, and noninvasive. These data provide direct and strong experimental evidence indicating that hyperactivation of the ras signaling pathway is responsible for the low-grade, noninvasive papillary bladder tumors (Figure 7).

In direct support of our transgenic data is the recent finding that humans with Costello syndrome, which is caused by germline mutations in the Ha-ras gene, are highly predisposed to developing earlyonset bladder tumors (64). Interestingly, all 3 cases of bladder tumors reported so far are of low pathological grade, papillary, and recurrent (65-67). These data strongly and independently support the role of ras activation in this distinct phenotypic pathway of bladder tumorigenesis.

Coactivation of AKT and STAT pathways is required for urothelial tumorigenesis. We observed that during Ha-ras hyperactivation, the preferential activation of certain signaling pathways is essential for urothelial tumor initiation. While activation of the MAPK pathway was sufficient to induce simple urothelial hyperplasia, as observed in heterozygous mice, this pathway alone did not lead to urothelial tumor initiation (Figures 3-6 and Figure 7). In contrast, the AKT pathway underwent profound changes only in the homozygous mice that exhibited severe nodular hyperplasia and urothelial tumors (Figure 5). These changes in AKT included its phosphorylation at both Thr308 and Ser473, nuclear translocation, and activation of its downstream targets (GSK3B and FKHR). These findings suggest that activation of the AKT pathway is crucial for urothelial tumor initiation (Figure 7). Interestingly, there was a strong association between AKT overactivation and the phosphorylation of the $\mathrm{C}$ terminus of PTEN (Figure 5). PTEN is a membrane-associated lipid phosphatase that suppresses PI3K by lowering the level of phosphatidylinositol-3phosphate, thereby inhibiting AKT activity (47). Phosphorylation of PTEN at the $C$ terminus in vitro prevents the recruitment of the protein from the cytosol to the plasma membrane, thus reducing PTEN's phosphatase activity $(50,68)$. What we observed here, however, provides new evidence that such a phosphorylation-mediated inactivation of PTEN occurs naturally in tumor cells and in the 
context of Ha-ras hyperactivation. Although ras itself is capable of activating the AKT pathway by directly interacting with the regulatory subunit of PI3K (69), inactivating a potent upstream inhibitor, PTEN, within the signaling pathway could be regarded as an additional safeguard employed by tumor cells to free themselves from the "check and balance" and to allow for signal amplification to go forward. Similarly, the cooperativity between ras activation and loss of PTEN allele(s) has recently been shown from transgenic models of skin and ovarian tumorigenesis $(70,71)$, suggesting that this mechanism is not confined to the urothelium. In human bladder tumors, while somatic mutations of PTEN are rare, loss of heterozygosity of the PTEN locus is fairly common, occurring in about $25 \%$ of the cases (72-74). Our study suggests yet another mechanism whereby PTEN can be inactivated during urothelial tumor formation. This underscores the importance of studying the functional status of PTEN when assessing the involvement of this protein in the tumorigenesis of bladder and other tissues (Figure 7).

In addition to AKT overactivation, we also observed a profound activation of STAT3 and STAT5, as evidenced by their elevated expression and phosphorylation, almost exclusively in the homozygous Ha-ras mice (Figure 6). As members of the latent STAT gene family, STAT3 and STAT5 are considered oncogenes that are persistently activated in a variety of tumors in response to growth factors and cytokines produced by the extracellular matrix (40). Phosphorylation of STAT3 and STAT5 promotes homotetramerization and nuclear translocation of the proteins and increases transcription of targets critical for cell growth, survival, and angiogenesis (40). The fact that these 2 proteins were not activated at all during simple hyperplasia of the heterozygous ras mice but were markedly activated in nodular hyperplasia and tumors where a substantial amount of extracellular matrix comes in close contact with the tumor cells reflects the importance of signaling crosstalk between transformed urothelial cells and their microenvironment in establishing and maintaining tumor growth (Figure 7). Another possible mechanism of STAT activation may be related to the functional inactivation of PTEN, which normally inhibits not only the PI3K/AKT pathway, but also the STAT pathway $(48,75)$. Given the remarkable degree of AKT and STAT activation in low-grade, noninvasive urothelial tumors, selectively inhibiting these molecules and/or restoring the function of their upstream antagonist such as PTEN will likely have an important therapeutic effect in treating and preventing the recurrence of this type of bladder tumor.

\section{Methods}

Transgenic and knockout mice. UPII/Ha-ras-M transgenic mice were produced to express a constitutively active rabbit Ha-ras protooncogene (codon Q61L) under the control of a $3.6-\mathrm{kb}$ mouse UPII promoter (24). This ras mutant was previously shown to share all the functional characteristics of codon 12 and 13 mutants and to be fully capable of transforming cultured NIH $3 \mathrm{~T} 3$ cells (76). Urothelium-specific expression of the transgene mutant was established by RT-PCR, Western blotting, and immunohistochemical staining. One of the transgenic lines that harbored 1 copy of the UPII/Ha-ras-M transgene (previously referred to as a "low-copy" line; ref. 24) was used as a starting material for intra- and intercrossing in this study. Southern blotting of NcoI-digested tail DNA using a probe located at the $3^{\prime}$ end of the UPII promoter was used to identify a transgene fragment $(1.7 \mathrm{~kb})$ and an endogenous UPII gene fragment $(1.4 \mathrm{~kb})$. The $\mathrm{X}$-films containing the 2 gene fragments were scanned to quantify the transgene dosage in reference to the endogenous gene. In heterozygous mice, the ratio of the transgene to the endogenous UPII gene was approximately 1:2. Intercrossing heterozygous mice produced homozygous mice, which harbored twice as much transgene as the heterozygous counterparts, as evidenced by the 1:1 ratio of the transgene to the endogenous UPII gene in the homozygotes.

Ink4a/Arf-knockout mice were obtained from Ronald DePinho (Harvard Medical School, Boston, Massachusetts, USA) (45). Since exons 2 and 3 of the Ink $4 a$ gene in these mice were replaced by a neo gene, the mice did not express p16Ink4a or p19Arf, 2 spliced variants of the Ink4a gene. Genotyping was performed using Southern blotting of PstI-digested tail DNA with "probe A," which detected a 9.2-kb wild-type allele and a 6.0-kb knockout allele. For analysis of the potential synergism between ras activation and Ink $4 a / A r f$ deficiency, UPII/Ha-ras-M heterozygous mice were crossed to homozygous Ink4a/Arf-knockout mice. Offspring heterozygous for both genotypes were backcrossed to the Ink4a/Arf-knockout mice to yield mice heterozygous for the UPII/Ha-ras-M transgene and nullizygous for Ink4a/Arf. All experiments on animals received prior approval from the institutional animal care and use committee of New York University School of Medicine and conformed to the standards set by appropriate regulatory agencies.

Real-time quantitative PCR. The expression of $\mathrm{p} 16 \mathrm{Ink} 4 \mathrm{a}$, p19Arf, and rabbit Ha-ras transgene mutant in mouse urothelia was quantified on an mRNA level by real-time quantitative PCR using a LightCycler RNA amplification kit (Roche Diagnostics). Total RNAs were extracted using an RNA extraction kit (Promega) from mouse urothelia exhibiting normal morphology, simple urothelial hyperplasia, or low-grade superficial papillary tumors; reverse-transcribed; and used as templates. Standards for quantification were generated for each gene in the form of plasmids. Thus, p16Ink4a and p19Arf cDNAs were obtained using RT-PCR from high-grade bladder tumors of double transgenic mice expressing both an activated Ha-ras and a SV40 large $\mathrm{T}$ antigen. The cDNAs were sequence verified and cloned into a pCRII TA cloning vector (Invitrogen). For rabbit Ha-ras quantification, a plasmid harboring the UPII/Ha-ras-M transgene (24) was used. These 3 plasmids were serially diluted (at $2 \mathrm{ng} / \mu \mathrm{l}, 1 \mathrm{ng} / \mu \mathrm{l}, 100 \mathrm{pg} / \mu \mathrm{l}, 10$ $\mathrm{pg} / \mu \mathrm{l}, 1 \mathrm{pg} / \mu \mathrm{l}$, and $0.1 \mathrm{pg} / \mu \mathrm{l}$ ) and used as standards to generate amplification curves during real-time PCR. Oligonucleotide primers used were: p16-forward, 5'-AGTCCGCTGCAGACAGACTG-3'; p19-forward, 5'-CTTGGTCACTGTGAGGATTC-3'; p16- and p19-reverse (common primer), 5'-CGGGAGAAGGTAGTGGGGTC-3'; rabbit Ha-ras-forward, CGGCGGTGTAGGCAAGAGCGC-3'; and rabbit Ha-ras-reverse, 5'-TCTTGGCCGAGGTCTCGATA-3'. PCR-amplified products for p16Ink4a were detected by 2 specific internal probes labeled with FITC (5'-GCCGTGTGCATGACGTG-FITC-3') or with LCRed640 (5'-LCRed640-GGCACTGCTGGAAGCCG-3'), respectively. p19Arf products were also detected by 2 specific internal probes (5'-TCCCGGAGACCCAGGACA-FITC-3' and 5'-LCRed640-GAGCTGCGCTCTGGCT-3'). Product of rabbit Ha-ras was detected by direct incorporation of an intercalating fluorescent dye (SYBR Green I; Roche) into newly amplified DNA during PCR. Housekeeping gene product GAPDH was amplified in parallel as a normalization control by direct SYBR Green I incorporation using 2 specific primers (forward: 5'-TCATGACCACAGTCCATGCC-3'; reverse: 5'-TGAATACGGCTACAGCAACAG- $3^{\prime}$ ). The PCR conditions were as follows: initial cycle at $95^{\circ} \mathrm{C}$ for 30 seconds; 50 cycles at $95^{\circ} \mathrm{C}$ for 5 seconds, $60^{\circ} \mathrm{C}$ for 15 seconds, and $72^{\circ} \mathrm{C}$ for extension whose duration was calculated based on the formula product length (bp) $/ 25$ = seconds. A calibration curve was run in parallel with each analysis and samples were quantified accordingly (LightCycler Software, version 3.5; Roche) and standardized for GAPDH.

Expression microarray analysis. Total RNAs were isolated from pooled normal urothelia of 10 wild-type mice; from pooled urothelial hyperplasia of 5 UPII/Ha-ras-M transgenic mice; and from individual, low-grade papillary bladder tumors of 2 transgenic mice. mRNAs were reverse transcribed, and after the synthesis of the second-strand cDNA, the double-stranded cDNAs were transcribed in vitro to synthesize biotin-labeled cRNA. The labeled 
cRNA was then hybridized to the GeneChip Mouse Genome 4302.0 arrays (Affymetrix). A single 4302.0 array contains 45,000 probe sets representing more than 39,000 transcripts and variants from more than 34,000 wellcharacterized mouse genes as well as uncharacterized expressed sequence tags (ESTs). Each gene is represented by at least 11 probe sets, thus allowing multiple independent measurements for high accuracy and reproducibility. Data analyses for over- and underexpressed genes were done by Genome Explorations using GeneChip Operating Software (Affymetrix).

Histochemical detection of senescence-associated $\beta$-galactosidase. Freshly dissected mouse bladders from wild-type and transgenic mice were fixed in $4 \%$ paraformaldehyde in phosphate buffer ( $\mathrm{pH} 7.0$ ), embedded in OCT medium, and frozen in liquid nitrogen. Ten-micrometer-thick cryosections were prepared from the frozen blocks and were incubated at $37^{\circ} \mathrm{C}$ overnight in a staining solution containing $1 \mathrm{mg} / \mathrm{ml} \mathrm{X-gal} \mathrm{(Sigma-Aldrich),}$ $5 \mathrm{mM} \mathrm{K}_{3} \mathrm{Fe}(\mathrm{CN})_{6}, 5 \mathrm{mM} \mathrm{K}_{4} \mathrm{Fe}(\mathrm{CN}), 150 \mathrm{mM} \mathrm{NaCl}$, and $2 \mathrm{mM} \mathrm{MgCl}_{2}$ in PBS ( $\mathrm{pH}$ 6.0). Control experiments were carried out simultaneously using adjacent sections to detect non-senescence-associated $\beta$-galactosidase activity with the same solution made in acidic $\mathrm{pH}$ (4.0; ref. 43). The sections were counterstained with $1 \%$ neutral red and examined by light microscopy.

Western blot analysis. Urinary bladders from wild-type and transgenic mice were turned inside out, and the urothelial cells were scraped off using a chemical spatula into phosphate-buffered saline. The cells were collected by centrifugation, and a protein extraction buffer was added to a final concentration of $20 \mathrm{mM}$ HEPES buffer ( $\mathrm{pH} 7.5$ ), $150 \mathrm{mM} \mathrm{NaCl}, 1 \%$ Triton $\mathrm{X}$-100, 1 mM EGTA, 1 mM EDTA, $1 \mathrm{mM}$ PMSF, $1 \mu \mathrm{g} / \mathrm{ml}$ aprotinin, $1 \mu \mathrm{g} / \mathrm{ml}$ leupeptin, $1.5 \mathrm{mM} \mathrm{MgCl}_{2}, 10 \%$ glycerol, $10 \mathrm{mM}$ sodium pyrophosphate, $50 \mathrm{mM} \mathrm{NaF}$, and $2 \mathrm{mM}$ sodium orthovanadate. For protein extraction from bladder neoplasms, tumors were removed from bladder surface and homogenized using a Polytron in the same extraction buffer mentioned above. Protein concentration was determined using BCA reagent (Pierce Biotechnology) with BSA as a standard. One hundred micrograms of the total urothelial proteins were reconstituted with SDS sample buffer and resolved by $10 \%$ SDS-PAGE, transferred onto a PVDF-Immobilon membrane, and blotted with various antibodies (see below). After incubation with secondary antibodies conjugated with HRP, the blots were developed in an ECL detection solution (ECL; Amersham Biosciences) and exposed to an X-ray film. Primary antibodies against p16Ink4a, p19Arf, and pan- ras were purchased from EMD Biosciences; those against MAPK, p-MAPK (Thr202/Tyr204), AKT, p-AKT (Thr308), p-AKT (Ser473), p-GSK3B (S9), p-FKHR (S256), STAT3, p-STAT3 (Tyr705), STAT-5, p-STAT5 (Tyr694), PTEN, p-PTEN (Ser380) were purchased from Cell Signaling Technology; and antibody against $\beta$-actin was purchased from Sigma-Aldrich.

Histology and immunohistochemistry. Bladder tissues were fixed in $10 \%$ buffered formalin and processed routinely for paraffin embedding, sectioning, and staining by $\mathrm{H} \& \mathrm{E}$. For immunohistochemical staining, deparaffinized sections were microwaved in citrate buffer $(\mathrm{pH} 6.0)$ at maximum power output for 10 minutes and stained with primary antibodies (see above; rabbit anti-VEGF from Santa Cruz Biotechnology Inc.) and secondary antibodies conjugated with HRP. The staining was visualized by developing the tissue sections in a solution containing $3,3^{\prime}$-diaminobenzidine tetrahydrochloride, followed by light counterstaining in a hematoxylin solution.

Statistics. Statistical analyses were performed using the Web-based SPSS software. Two-tailed Student's $t$ test was employed to assess the statistical difference in activated rabbit Ha-ras expression between homo- and heterozygous mice. Tumor-free rate curves for hetero- and homozygous mice were constructed according to the Kaplan-Meier method. $P$ values less than or equal to 0.05 were considered statistically significant.

\section{Acknowledgments}

This work was supported by grants from the NIH (DK52206, DK56903, and DK69688) and the Medical Research Service of the Veterans Affairs Administration (Merit Review). The authors would like to thank Gordon Cook for his artwork in Figure 7.

Received for publication August 15, 2006, and accepted in revised form November 27, 2006.

Address correspondence to: Xue-Ru Wu, Department of Urology, New York University School of Medicine, Manhattan Veterans Affairs Medical Center, 423 E. 23rd St., Room 18604S, New York, New York, USA. Phone: (212) 951-5429; Fax: (212) 951-5424; E-mail:xue-ru.wu@med.nyu.edu.

\section{Lan Mo and Xiaoyong Zheng contributed equally to this work.}

1. Malumbres, M., and Barbacid, M. 2001. To cycle or not to cycle: a critical decision in cancer. Nat. Rev. Cancer. 1:222-231.

2. Sharpless, N.E., and DePinho, R.A. 2005. Cancer: crime and punishment. Nature. 436:636-637.

3. Guerra, C., et al. 2003. Tumor induction by an endogenous K-ras oncogene is highly dependent on cellular context. Cancer Cell. 4:111-120.

4. Schwab, M. 1999. Oncogene amplification in solid tumors. Semin. Cancer Biol. 9:319-325.

5. Lowe, S.W., Cepero, E., and Evan, G. 2004. Intrinsic tumour suppression. Nature. 432:307-315.

6. Reddy, E.P., Reynolds, R.K., Santos, E., and Barbacid, M. 1982. A point mutation is responsible for the acquisition of transforming properties by the T24 human bladder carcinoma oncogene. Nature. 300:149-152.

7. Parada, L.F., Tabin, C.J., Shih, C., and Weinberg, R.A. 1982. Human EJ bladder carcinoma oncogene is homologue of Harvey sarcoma virus ras gene. Nature. 297:474-478.

8. Malumbres, M., and Barbacid, M. 2003. RAS oncogenes: the first 30 years. Nat. Rev. Cancer. 3:459-465.

9. Feinberg, A.P., Vogelstein, B., Droller, M.J., Baylin, S.B., and Nelkin, B.D. 1983. Mutation affecting the 12 th amino acid of the c-Ha-ras oncogene product occurs infrequently in human cancer. Science. 220:1175-1177.

10. Fitzgerald, J.M., et al. 1995. Identification of H-ras mutations in urine sediments complements cytology in the detection of bladder tumors. J. Natl. Cancer Inst. 87:129-133.

11. Czerniak, B., et al. 1992. Concurrent mutations of coding and regulatory sequences of the Ha-ras gene in urinary bladder carcinomas. Hum. Pathol. 23:1199-1204.

12. Przybojewska, B., Jagiello, A., and Jalmuzna, P. 2000. H-RAS, K-RAS, and N-RAS gene activation in human bladder cancers. Cancer Genet. Cytogenet. 121:73-77.

13. Theodorescu, D., Cornil, I., Fernandez, B.J., and Kerbel, R.S. 1990. Overexpression of normal and mutated forms of HRAS induces orthotopic bladder invasion in a human transitional cell carcinoma. Proc. Natl. Acad. Sci. U. S. A. 87:9047-9051.

14. Masui, T., et al. 1991. H-ras mutations in rat urinary bladder carcinomas induced by N-[4-(5-nitro2-furyl)-2-thiazolyl]formamide and sodium saccharin, sodium ascorbate, or related salts. Cancer Res. 51:3471-3475.

15. Jebar, A.H., et al. 2005. FGFR3 and Ras gene mutations are mutually exclusive genetic events in urothelial cell carcinoma. Oncogene. 24:5218-5225.

16. Vageli, D., et al. 1996. Transcriptional activation of $\mathrm{H}$-ras, $\mathrm{K}$-ras and $\mathrm{N}$-ras proto-oncogenes in human bladder tumors. Cancer Lett. 107:241-247.

17. Ye, D.W., Zheng, J.F., Qian, S.X., and Ma, Y.J. 1993. Correlation between the expression of oncogenes ras and c-erbB-2 and the biological behavior of bladder tumors. Urol. Res. 21:39-43.

18. Ornitz, D.M., and Marie, P.J. 2002. FGF signaling pathways in endochondral and intramembranous bone development and human genetic disease. Genes Dev. 16:1446-1465.

19. Cappellen, D., et al. 1999. Frequent activating mutations of FGFR3 in human bladder and cervix carcinomas. Nat. Genet. 23:18-20.

20. Rieger-Christ, K.M., et al. 2003. Identification of fibroblast growth factor receptor 3 mutations in urine sediment DNA samples complements cytology in bladder tumor detection. Cancer. 98:737-744.

21. van Rhijn, B.W., et al. 2004. FGFR3 and P53 characterize alternative genetic pathways in the pathogenesis of urothelial cell carcinoma. Cancer Res. 64:1911-1914.

22. Wolff, E.M., Liang, G., and Jones, P.A. 2005. Mechanisms of disease: genetic and epigenetic alterations that drive bladder cancer. Nat. Clin. Pract. Urol. 2:502-510.

23. Wu, X.R. 2005. Urothelial tumorigenesis: a tale of divergent pathways. Nat. Rev. Cancer. 5:713-725.

24. Zhang, Z.T., et al. 2001. Role of Ha-ras activation in superficial papillary pathway of urothelial tumor formation. Oncogene. 20:1973-1980.

25. Sherr, C.J. 2001. The INK4a/ARF network in tumour suppression. Nat. Rev. Mol. Cell Biol. 2:731-737.

26. Lin, A.W., et al. 1998. Premature senescence involv- 
ing p53 and p16 is activated in response to constitutive MEK/MAPK mitogenic signaling. Genes Dev. 12:3008-3019.

27. Serrano, M., Lin, A.W., McCurrach, M.E., Beach, D., and Lowe, S.W. 1997. Oncogenic ras provokes premature cell senescence associated with accumulation of p53 and p16INK4a. Cell. 88:593-602.

28. Collado, M., et al. 2005. Tumour biology: senescence in premalignant tumours. Nature. 436:642.

29. Braig, M., et al. 2005. Oncogene-induced senescence as an initial barrier in lymphoma development. Nature. 436:660-665.

30. Chin, L., et al. 1997. Cooperative effects of INK4a and ras in melanoma susceptibility in vivo. Genes Dev. 11:2822-2834.

31. Fisher, G.H., et al. 2001. Induction and apoptotic regression of lung adenocarcinomas by regulation of a K-Ras transgene in the presence and absence of tumor suppressor genes. Genes Dev. 15:3249-3262.

32. Aguirre, A.J., et al. 2003. Activated Kras and Ink4a/ Arf deficiency cooperate to produce metastatic pancreatic ductal adenocarcinoma. Genes Dev. 17:3112-3126.

33. Uhrbom, L., Kastemar, M., Johansson, F.K., Westermark, B., and Holland, E.C. 2005. Cell typespecific tumor suppression by Ink4a and Arf in Kras-induced mouse gliomagenesis. Cancer Res. 65:2065-2069.

34. Obermann, E.C., et al. 2003. Frequent genetic alterations in flat urothelial hyperplasias and concomitant papillary bladder cancer as detected by CGH, LOH, and FISH analyses. J. Pathol. 199:50-57.

35. Chow, N.H., et al. 2000. Papillary urothelial hyperplasia is a clonal precursor to papillary transitional cell bladder cancer. Int. J. Cancer. 89:514-518.

36. Baud, E., Catilina, P., and Bignon, Y.J. 1999. p16 involvement in primary bladder tumors: analysis of deletions and mutations. Int. J. Oncol. 14:441-445.

37. Gonzalez-Zulueta, M., et al. 1995. Methylation of the $5^{\prime} \mathrm{CpG}$ island of the $\mathrm{p} 16 / \mathrm{CDKN} 2$ tumor suppressor gene in normal and transformed human tissues correlates with gene silencing. Cancer Res. 55:4531-4535.

38. Shields, J.M., Pruitt, K., McFall, A., Shaub, A., and Der, C.J. 2000. Understanding Ras: 'it ain't over 'til it's over'. Trends Cell Biol. 10:147-154.

39. Downward, J. 2003. Targeting RAS signalling pathways in cancer therapy. Nat. Rev. Cancer. 3:11-22.

40. Yu, H., and Jove, R. 2004. The STATs of cancer new molecular targets come of age. Nat. Rev. Cancer. 4:97-105.

41. Sharpless, N.E., et al. 2001. Loss of p16Ink4a with retention of p19Arf predisposes mice to tumorigenesis. Nature. 413:86-91.

42. Barradas, M., et al. 2002. Identification of a candidate tumor-suppressor gene specifically activated during Ras-induced senescence. Exp. Cell Res. 273:127-137.
43. Going, J.J., Stuart, R.C., Downie, M., FletcherMonaghan, A.J., and Keith, W.N. 2002. 'Senescenceassociated' beta-galactosidase activity in the upper gastrointestinal tract. J. Pathol. 196:394-400.

44. Hartmann, A., et al. 1999. Frequent genetic alterations in simple urothelial hyperplasias of the bladder in patients with papillary urothelial carcinoma. Am. J. Pathol. 154:721-727.

45. Serrano, M., et al. 1996. Role of the INK4a locus in tumor suppression and cell mortality. Cell. 85:27-37.

46. Walker, B.E. 1960. Renewal of cell populations in the female mouse. Am. J. Anat. 107:95-105.

47. Cully, M., You, H., Levine, A.J., and Mak, T.W. 2006. Beyond PTEN mutations: the PI3K pathway as an integrator of multiple inputs during tumorigenesis. Nat. Rev. Cancer. 6:184-192.

48. Sun, S., and Steinberg, B.M. 2002. PTEN is a negative regulator of STAT3 activation in human papillomavirus-infected cells. J. Gen. Virol. 83:1651-1658.

49. Nguyen, K.T., et al. 2002. The role of phosphatidylinositol 3-kinase, rho family GTPases, and STAT3 in Ros-induced cell transformation. J. Biol. Chem. 277:11107-11115.

50. Torres, J., and Pulido, R. 2001. The tumor suppressor PTEN is phosphorylated by the protein kinase CK2 at its C terminus. Implications for PTEN stability to proteasome-mediated degradation. J. Biol. Chem. 276:993-998.

51. Vazquez, F., Ramaswamy, S., Nakamura, N., and Sellers, W.R. 2000. Phosphorylation of the PTEN tail regulates protein stability and function. Mol. Cell. Biol. 20:5010-5018.

52. Chin, L., et al. 1999. Essential role for oncogenic Ras in tumour maintenance. Nature. 400:468-472.

53. van Oers, J.M., et al. 2006. Chromosome 9 deletions are more frequent than FGFR3 mutations in flat urothelial hyperplasias of the bladder. Int. J. Cancer. 119:1212-1215.

54. Le Frere-Belda, M.A., et al. 2001. p15(Ink4b) in bladder carcinomas: decreased expression in superficial tumours. Br. J. Cancer. 85:1515-1521.

55. Gao, J., et al. 2004. p53 deficiency provokes urothelial proliferation and synergizes with activated Ha-ras in promoting urothelial tumorigenesis. Oncogene. 23:687-696.

56. Koss, L.G. 1998. Natural history and patterns of invasive cancer of the bladder. Eur. Urol. 33:2-4.

57. Knowles, M.A. 2006. Molecular subtypes of bladder cancer: Jekyll and Hyde or chalk and cheese? Carcinogenesis. 27:361-373.

58. Cohen, S.M. 2002. Comparative pathology of proliferative lesions of the urinary bladder. Toxicol. Pathol. 30:663-671.

59. Dinney, C.P., et al. 2004. Focus on bladder cancer. Cancer Cell. 6:111-116.

60. Van Dyke, T., and Jacks, T. 2002. Cancer modeling in the modern era: progress and challenges. Cell.
108:135-144.

61. Dalbagni, G., Presti, J., Reuter, V., Fair, W.R., and Cordon-Cardo, C. 1993. Genetic alterations in bladder cancer. Lancet. 342:469-471.

62. Grossman, H.B., et al. 1998. p53 and Rb expression predict progression in T1 bladder cancer. Clin. Cancer Res. 4:829-834.

63. Cote, R.J., et al. 1998. Elevated and absent pRb expression is associated with bladder cancer progression and has cooperative effects with $\mathrm{p} 53$. Cancer Res. 58:1090-1094.

64. Aoki, Y., et al. 2005. Germline mutations in HRAS proto-oncogene cause Costello syndrome. Nat. Genet. 37:1038-1040.

65. Franceschini, P., et al. 1999. Bladder carcinoma in Costello syndrome: report on a patient born to consanguineous parents and review. Am. J. Med. Genet. 86:174-179.

66. Gripp, K.W., Scott, C.I., Jr., Nicholson, L., and Figueroa, T.E. 2000. Second case of bladder carcinoma in a patient with Costello syndrome. Am.J. Med. Genet. 90:256-259.

67. Urakami, S., et al. 2002. Recurrent transitional cell carcinoma in a child with the Costello syndrome. J. Urol. 168:1133-1134.

68. Vazquez, F., et al. 2006. Tumor suppressor PTEN acts through dynamic interaction with the plasma membrane. Proc. Natl. Acad. Sci. U. S. A. 103:3633-3638.

69. Luo, J., Manning, B.D., and Cantley, L.C. 2003. Targeting the PI3K-Akt pathway in human cancer: rationale and promise. Cancer Cell. 4:257-262.

70. Yao, D., et al. 2006. PTEN loss promotes rasHamediated papillomatogenesis via dual up-regulation of AKT activity and cell cycle deregulation but malignant conversion proceeds via PTEN-associated pathways. Cancer Res. 66:1302-1312.

71. Dinulescu, D.M., et al. 2005. Role of K-ras and Pten in the development of mouse models of endometriosis and endometrioid ovarian cancer. Nat. Med. 11:63-70.

72. Wang, D.S., et al. 2000. Molecular analysis of PTEN and MXI1 in primary bladder carcinoma. Int.J. Cancer. 88:620-625.

73. Cairns, P., et al. 1998. Point mutation and homozygous deletion of PTEN/MMAC1 in primary bladder cancers. Oncogene. 16:3215-3218.

74. Tanaka, M., and Grossman, H.B. 2003. In vivo gene therapy of human bladder cancer with PTEN suppresses tumor growth, downregulates phosphorylated Akt, and increases sensitivity to doxorubicin. Gene Ther. 10:1636-1642.

75. Nguyen, P.L., et al. 1994. Expression of epidermal growth factor receptor in invasive transitional cell carcinoma of the urinary bladder. A multivariate survival analysis. Am. J. Clin. Pathol. 101:166-176.

76. Corominas, M., et al. 1991. ras activation in human tumors and in animal model systems. Environ. Health Perspect. 93:19-25. 